\title{
Study of effects of constant observation of psychiatric in-patients
}

\author{
Olakunle Ashaye, George Ikkos and Elizabeth Rigby
}

\begin{abstract}
Constant observation is used in psychiatric practice mainly to prevent acutely III in-patients from self-harm. All in-patients in a psychiatiric hospltal and a general hospltal psychlatilic unit who had been on constant observation over a 6 month period were identified (13 patients). These patients and their primary nurses were interviewed using different questionnaires. Most patients felf they had beneffted from being on constant observation, but dilstiked the intrusion on their privacy. The nurses agreed that it had helped most patients, but a significant number of nurses found it frustrating and stresstul. Our results sugcest a need for an information sheet to be given to patients placed on constant observation; that the period on constant observation should be reduced where poselble, and that support should be provided for the nurses involved.
\end{abstract}

Constant observation is used in psychiatric services for in-patients in various circumstances. The Royal College of Nursing (RCN) has referred to constant observation as 'special observation'. RCN guidelines (1995) on indications for special observation include patients at risk of self-harm, and patients at risk of harming others through their behaviour. Constant observation is maintained at a patient to nurse ratio of $1: 1$, with the patient being at arms length and the observing nurse being fully aware of the patient all the time. Although such observation is frequently employed, there is still no uniformity among hospitals of the name given to constant observation and little research has been done to evaluate its usefulness (Shugar \& Rehaluk, 1990). In our hospitals, the term 'continuous care' is used, as it is felt that it entails more than just observing. A therapeutic relationship with the patient is expected.

Another area of concern is the cost effectiveness of a mode of care that requires increased staffing levels. It is not unusual for hospitals to take on temporary staff, who may not be familiar with the definitions and roles of particular levels of observation.

\section{The study}

The review was done in acute adult psychiatric wards, at Barnet General and Napsbury Hospitals. The Barnet General Hospital's psychiatric unit has 75 beds and Napsbury Hospital is a psychiatric hospital with 484 beds. Both hospitals are under the same health trust and nine miles apart, with their catchment area covering the outer London borough of Barnet and part of the county of Hertfordshire.

The study involved designing two questionnaires, one for patients and one for their respective primary nurses. All patients who came off constant observation within the six month study period were interviewed. The patients questionnaire contained questions about reasons for being on constant observation, benefits of constant observation and ways patients would have preferred it to have been carried out. The nurses' questionnaire contained similar questions to those of the patients together with questions about the RCN guidelines. The questionnaires were developed by a team consisting of a consultant psychiatrist, two nurse managers, an audit officer and a psychiatric trainee. The primary aim was to gather as much information as possible, to identify issues of importance to both nurses and patients. As a result, some questions were open-ended.

The patients were interviewed by a psychiatric trainee and a senior nurse. The key nurses were interviewed by the audit officer and a senior nurse. None of the interviewers worked on the same wards as either patients or nurses.

Before the interviews, the consent of each patient was obtained and their consultants gave written permission for interviews to be carried out. Those interviewed were all reassured that informants would remain anonymous.

\section{Findings}

The 13 patients interviewed consisted of four men and nine women, with an age range of 20-60 years. Seven patients were single, three were 
Table 1. Views of patients on their experiences of constant observation

Positive experiences
Eleven felt they were on it to prevent self-harm and
benefited from it
Nine patients believed they needed to be constantly
observed
Nine patients were satisfied with their interactions with
nursing staff
Eight patients said they recelved information about
constant observation
Negative experiences
Eight patients disliked the intrusion of their privacy,
especially in the tollets
Five patients did not remember receiving any
information on constant observation
Four patients felt there were no activities available for
them
Suggestions for change
Privacy in the toilets
Reduction in the length of time for constant
observation
Non-use of part-time staff who were unfamillar with
patients

Table 2. Views of the key nurses of patients placed on constant observation

Postive experiences
All nurses said their patients had recelved information
about constant Observation
Eleven nurses felt constant observation had been
used to prevent self-harm
Ten nurses said their patients engaged in ward
activities while on constant observation
Negative experiences
Six nurses found their patients' unpredictable and
threatening behaviour stressful
Three nurses felt constant observation had been
inappropriately used to prevent absconding by
patients
suggestions for change
Placing patients on constant observation for no
longer than 48 hours
Placement of longer-term vulnerable patients in
secure wards or in a psychiatric intensive care unit

married, two were widowed and one divorced. One patient was of Afro-Carribean origin with the rest being Caucasian.

The clinical diagnoses included eight patients with schizophrenia, four with recurrent depressive disorder, and one with a psychotic disorder secondary to alcohol misuse. Ten patients had previous psychiatric admissions, with six of them having been placed on constant observa- tion in their past admissions. Six patients were admitted for compulsory treatment under Section 3 of the Mental Health Act (1983). The others were admitted as voluntary patients.

The length of constant observation ranged from one day to four months, with nine patients on it for less than five days, and one patient each on it for one, two, three and four months respectively. The views of patients and their key nurses on the experience of constant observation are summarised in Tables 1 and 2.

\section{Comment}

This preliminary study on constant observation revealed some of the experiences of patients and their key nurses. Though limited by the small sample size, it gave us the opportunity to review our practice and improve our questionnaires for a future, larger study.

The views of several writers, including the $\mathrm{RCN}$, is that constant observation is to prevent self-harm or suicide in vulnerable mentally ill inpatients (Goldberg, 1989; Shugar \& Rehaluk, 1990; Duffy, 1995; Thomas, 1995). It was the most frequent reason for placing our patients on constant observation.

The RCN guidelines on constant observation were similar to those being used by the nurses at the time of this study. They include explaining to patients what constant observation means and the review procedures. All 13 nurses said patients were given information on constant observation, but only eight patients remembered receiving any information. It was also noted that there was a lack of documentary evidence that such information had been passed on to patients. In response to this problem, an information sheet for patients on constant observation was designed. It is expected that in future, apart from giving the usual information verbally, patients would have the sheet on constant information to be able to remind themselves of what it entailed.

This study suggests a need to reduce the period of constant observation to a minimum. Nurses may benefit from individual support or involvement in a support group. Early transfer to more secure units should be considered for the more chronic and problematic patients.

As a result of this study the following changes have taken place in our service:

(1) A constant observation form has been designed for nursing and medical staff to complete which incorporates instructions on how to carry out the necessary observation and care.

(2) An information leaflet has been designed and is made available for patients on constant observation. 
(3) A new structured questionnaire for patients on constant observation has been designed for use in a future study of constant observation. The advantage of the new questionnaire is that, as well as giving opportunity to patients to expand their answers, they also have to answer yes/no questions, thus allowing the possibility of statistical analysis of results.

\section{Acknowledgments}

We wish to acknowledge the contributions of our medical and nursing colleagues, especially G. Lees, P. Kelly, S. OToole, J. Cahill and L. Mok without whose cooperation this study could not have been undertaken.

\section{References}

DuFry, D. (1995) Out of the shadows: a study of the special observation of suicidal psychiatric in-patients. Joumal of Advanced Nursing. 21. 944-950.
GolDBERG, R. (1989) The use of constant observation in general hospitals. International Joumal of Psychiatry in Medicine, 19, 193-201.

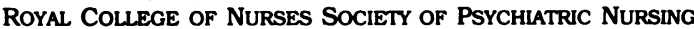
(1985) Guldelines on Observations. Information No. 5. London: RCN.

SHUGAR, G. \& REHALUK, R. (1990) Continuous observation for psychiatric in-patients: A critical evaluation. Comprehensive Psychiatry, 30, 48-55.

THOMAs, B. (1995) Supervising suicidal patients within a hospital setting. British Journal of Nursing, 4, 212-215.

* Olakunle Ashaye, Senior Registrar, London/ UCLSM Senior Registrar Training Scheme in Psychiatry of Old Age; George Ikkos, Consultant Psychiatrist, Psychiatric Unit, Barnet General Hospital, Wellhouse Lane, Barnet, Hertfordshire; and Elizabeth Rigby, Clinical Audit Co-Ordinator, Barnet Healthcare Trust

*Correspondence: Dr O. Ashaye, Department of Psychiatry, Princess Alexandra Hospital, Hamstel Road, Harlow, Essex CM20 19X 